\title{
Cronobiologia e suas Influências nas Vivências de Lazer ${ }^{1}$
}

\author{
Cronobiology and their Influences in the Leisure Experiences
}

Cronobiología y su Influencias en las Vivencias de el Ocio

\author{
Bianca Aparecida Araujo Pizzolito ${ }^{2}$ \\ Edmur Antonio Stoppa ${ }^{3}$
}

\begin{abstract}
Resumo
A exclusão no lazer, em geral, é estudada a partir de diversas variáveis, sendo as mais clássicas: renda, gênero, idade, escolaridade e inserção espacial. Este estudo abordou outra variável: a relação sono/vigília, questão estudada diretamente pela cronobiologia, área que estuda os ritmos biológicos, caracterizando os seres humanos em matutinos, vespertinos ou intermediários. $\mathrm{O}$ estudo verificou os possíveis impactos que esses ritmos biológicos exercem sobre o lazer dos indivíduos, assim como, as possíveis reordenações diárias das atividades de trabalho e lazer a que são submetidos por esta condição. O método utilizado foi a história oral, com a coleta de dados realizada por meio das técnicas da historia oral temática, contando com um roteiro de temas, entrevistas gravadas e transcritas. As principais considerações foram: uma vez que os horários sociais são essencialmente diurnos, os indivíduos matutinos não apontaram grande dificuldade em (re) organizar seus horários, para esses indivíduos as vivências de lazer noturnas ficam restritas, geralmente, a eventos de cunho social, enquanto as atividades de lazer pela manhã são mais individuais. Enquanto que com as pessoas vespertinas, foi possível identificar maior dificuldade de adequação aos horários sociais e um esforço de adaptação dos horários de maior disposição com os de produtividade. As atividades de lazer coincidiam com a oferta social de lazer, geralmente, nos períodos da tarde e da noite. Desta forma, verificou-se que embora exista um horário social, do qual participam diferentes indivíduos, existem características de um lazer matutino e um vespertino que são sustentadas no cotidiano e nos discursos.
\end{abstract}

Palavras-chave: lazer; sono; vigília; cronobiologia; trabalho.

\footnotetext{
${ }^{1}$ Agradecimento ao CNPq pelo fomento à pesquisa.

${ }^{2}$ Bacharel em Lazer e Turismo pela Escola de Artes, Ciências e Humanidades, da Universidade de São Paulo. Membro do Grupo Interdisciplinar em Estudos do Lazer (GIEL-EACH/USP). Técnica do grupo de pesquisa: Turismo, Conhecimento e Inovação (TCI- EACH/USP). E-mail: biancapizzolito@yahoo.com.br.

${ }^{3}$ Doutor em Educação Física, na área dos Estudos do Lazer, docente no curso de Lazer e Turismo, da Escola de Artes, Ciências e Humanidades (EACH/USP). Membro do Laboratório de Pesquisa sobre Formação e Atuação Profissional (ORICOLÉ/UFMG) e líder do Grupo de Pesquisa em Lazer (GPL/UNIMEP) e do Grupo Interdisciplinar de Estudos do Lazer (GIEL/USP). E-mail: stoppa@usp.br.
} 


\begin{abstract}
This research is about a variable without traditions in the leisure studies: the relationship between sleep/vigil. This question is studied directly by the cronobiology, an area in biology that classifies the people according to your cronotypes in Morningness or Eveningness people. So, the objective of this research was to study how the morningness/eveningness condition influences in the leisure practices, analyzing the possible ways of reordering the work and leisure routine that the people can agree being morningness or eveningness. The technique to obtain the information was the Oral History, using a roadmap issues and a recorder. The interviews was transcribed and analyzed. The research has five morningness participants, five eveningness participants. This research show us that the morningness people haven't a big difficult in organize your time because the social time are more morningness than eveningness. The night leisure experiences of this kind of people are limited, the most of these experiences correspond a social events and the morning leisure experiences are, usually, more individuals. The eveningness people show more difficult of adaptation in the social time, and the most of the participants have any compulsory activities in the morning. The bohemian leisure, related with bars and parties, is part of the speech of these people. The morningness and the eveningness people share the time of work and leisure, because there is a unique social time, but there is also specific characteristics of a morningness and an eveningness leisure that are present in all the interviews.
\end{abstract}

Keywords: leisure, sleep; vigil; cronobiology; work.

\title{
Resumen
}

Esta investigación es sobre la variable sin tradición en el estudio del tiempo libre: la relación entre dormir y estar activo. Esta pregunta es estudiada directamente por la cronobiología, un área en la biología que clasifica las personas de acuerdo a sus crono tipos; personas matutinas o vespertinas. El objetivo de esta investigación es estudiar como la condición matutino/vespertino influye en el ocio, analizando las posibles formas de reordenamiento del trabajo y de la rutina que las personas pueden acordar siendo matutinas o vespertinas. La técnica para obtener la información fue por medio oral, usando archivos escritos y una grabadora. Las entrevistas fueron transcritas y analizadas. La investigación cuenta con cinco participantes matutinos y cinco vespertinos. Esta búsqueda nos demuestra que las personas matutinas tienen la facilidad de organizar su tiempo; por el contrario las experiencias de las personas vespertinas son limitadas. La mayoría de las experiencias corresponden a eventos a los cuales asisten gran cantidad de personas. En el caso de las personas matutinas las experiencias son más individuales. Las personas vespertinas muestran más dificultad en la adaptación al tiempo, y la mayoría de participantes realiza alguna actividad matutina. Las actividades bohemias, relacionadas con bares y fiestas, son parte de la cotidianidad de estas personas. Las personas matutinas y vespertinas reparten su tiempo de trabajo y ocio, porque solo hay un tiempo social único, pero también hay características especiales en el tiempo libre de los matutinos y vespertinos que están presentes en todas las entrevistas.

Palavras claves: ócio; sueño; vigília; cronobiologia; trabajo. 


\section{Introdução}

A palavra lazer está a cada dia mais presente no cotidiano das pessoas, contudo a sua prática livre e efetiva está longe de ser democrática e irrestrita. Marcellino (2006, p. 24) pontua que "Uma série de preconceitos restringe a prática de lazer aos mais habilitados, aos mais jovens e aos que se enquadram dentro dos padrões estabelecidos de normalidade”.

É comum a confusão em relação ao papel do lazer na sociedade e em meio a isso, muitas vezes, sua prática acaba por assumir uma postura assistencialista, utilitarista ou alienadora. Contudo, o lazer pode ser entendido como um fator importante para a busca da qualidade de vida.

Nesse sentido, Marcellino (1987) entende o lazer como uma face da cultura vivenciada no tempo disponível das pessoas, que possui determinados valores, possibilitando condições de descanso, divertimento e desenvolvimento pessoal e que pressupõe a livre adesão.

Desta forma, dialoga-se com o entendimento do lazer como mais uma vivência cultural possuindo, assim, características sociais que variam de acordo com cada tempo e espaço.

Dumazedier (2004) aponta que o lazer possui três principais características: o descanso, o divertimento e o desenvolvimento pessoal e social, sendo assim, um tempo reservado para a autoformação e realização dos indivíduos. De acordo com ele,

O lazer permite uma participação social maior e mais livre, a prática de uma cultura desinteressada do corpo, da sensibilidade e da razão, além da formação prática e técnica; oferece novas possibilidades de integração voluntária à vida de agrupamentos recreativos, culturais e sociais, possibilita o desenvolvimento livre de atitudes adquiridas na escola, sempre ultrapassadas pela contínua e complexa evolução da sociedade e incita a adotar atividades ativas da utilização de fontes diversas de informação, tradicionais ou modernas (DUMAZEDIER, 2004, p. 33).

Deste modo, muitas vivências de lazer estão condicionadas a seu meio e, às vezes, pouco corresponde aos anseios individuais das pessoas. Sobre isso, Camargo pontua:

[...] seria uma ousadia afirmar que alguma ação humana é executada por livre escolha do indivíduo. Os determinismos culturais, sociais, políticos e econômicos, pesam sobre todas as atividades do cotidiano, inclusive sobre o lazer (1992, p. 10). 
E acrescenta "[...] que há um grau de liberdade nas escolhas dentro do lazer, maior que nas escolhas que se faz no trabalho, no ritual familiar, na vida sócio-religiosa e sócio-política" (1992, p. 10).

Assim, a decisão entre ir a um cinema ou ir a um passeio no parque envolve mais elementos do que a simples decisão pessoal. Podem estar envolvidas outras questões tais como costumes, crenças e, principalmente, a vontade ou as decisões de um grupo do qual se faz parte.

Outra questão importante, é que o tempo de lazer é, também, segundo Dumazedier (2004), limitado de acordo com obrigações e necessidades da vida cotidiana. Relaciona-se, principalmente, ao trabalho profissional, ao trabalho suplementar, aos trabalhos domésticos, às atividades de manutenção, como as refeições e o sono, às atividades rituais ligadas às obrigações sociais ou religiosas, como festas de aniversário, participação política e, ainda, às atividades ligadas aos estudos.

Com isso, apesar de ser um fenômeno atual e significativo, o lazer é, também, compactado por muitas esferas e, até, suprimido por outras. Então, faz-se necessário entender essas limitações, que de certa forma, impossibilitam a vivência do tempo livre de acordo com a individualidade e a subjetividade das pessoas.

Entender as possibilidades do lazer é, também, abrir portas às novas oportunidades, pois o mesmo não é um fenômeno estanque em um único período de espaço e tempo. É adaptável às diferentes vivências e definido de acordo com as particularidades de cada indivíduo.

A exclusão no lazer é, frequentemente, estudada a partir de diversas variáveis, sendo as mais clássicas: renda, gênero e idade. Essas variáveis configuram-se importantes para o entendimento do lazer por essa ótica, mas outras possibilidades de análise permitem diferentes relações e entendimento do lazer na vida de um indivíduo. Um exemplo disso é o das pessoas com deficiência, que se configura como variável transversal às três citadas anteriormente.

Esta pesquisa teve como foco uma variável, até então não explorada nos estudos de lazer, a relação sono/vigília. Esta é estudada, diretamente, pela cronobiologia que corresponde a uma área recente de pesquisa, a qual se propõe ao estudo dos ritmos biológicos (relógios internos que regulam nosso organismo) e as influências que o meio externo exerce sob estes. 
Os ritmos biológicos se caracterizam

[...] como expressão conjunta de fatores endógenos e exógenos (...) É um termo que reflete uma visão do ritmo endógeno como o verdadeiro ritmo, que poderia ser obscurecido o mascarado pelos fatores externos (ASCHOLF apud MENNA BARRETO; MARQUES, 2003, p. 40).

Neste contexto, a proposta da cronobiologia é, então, realizar:

[...] um estudo sistemático das características temporais da matéria viva, em todos os seus níveis de organização. Inclui o estudo dos ritmos biológicos, como por exemplo, as oscilações periódicas em variáveis biológicas e as mudanças associadas ao desenvolvimento (HALBERG apud MENNA BARRETO; MARQUES, 2003, p. 32).

A cronobiologia, segundo Menna Barreto e Marques (2003), surge em meados do século XX da necessidade de compartilhar as inúmeras informações coletadas em diferentes instâncias sobre o assunto, a fim de organizar e padronizar essas informações.

Em São Paulo é fundado, em 1981, o Grupo Multidisciplinar de Desenvolvimento e Ritmos Biológicos na Universidade de São Paulo, pioneiro em colocar a cronobiologia como objeto principal de estudo e hoje existem inúmeros periódicos e diversas instituições dedicados a esse tema.

Esse crescimento e reconhecimento abriram portas também a novas possibilidades e a diversas áreas de estudo, focando, então, o tema dos relógios biológicos. Assim, diversas manifestações rítmicas do ser humano passaram a ser melhor exploradas e compreendidas como um campo de pesquisa. O ciclo sono-vigília é uma delas.

Esse ciclo propõe a coexistência de ritmos internos e externos, constituindo um ritmo biológico específico deste ciclo. De acordo com Louzada e Menna Barreto (2007, p. 10) “Até recentemente, acreditávamos que (...) o sono era nossa resposta ao escuro e vigília à resposta ao claro".

Contudo, atualmente, é imprescindível destacar que existem balizas temporais internas e externas. Externamente, pautamos nosso tempo por algumas referências como depois do almoço, após a aula, entre outras situações e, internamente, também temos uma sequência de 
eventos ordenados no tempo, como picos hormonais, de temperatura corporal, etc. Essa sequência é, por sua vez, chamada de Organização Temporal Interna. (LOUZADA; MENNA BARRETO, 2007).

De acordo com essa organização, pode-se afirmar, segundo os mesmos autores, que o ser humano é essencialmente diurno. Contudo, o fato da espécie ser diurna não significa que exista um único padrão a que todas as pessoas se encaixem. Existem variações dessa classificação. Louzada e Menna Barreto tecem, sobre o tema, o seguinte comentário:

O horário preferido de início do episódio de sono noturno varia entre as pessoas. Algumas preferem iniciá-la mais cedo, são matutinas. Outras pessoas preferem dormir mais tarde e acordar mais tarde, são as chamadas de vespertinas [...]. As pessoas com preferências intermediárias são chamadas indiferentes. (LOUZADA; MENNA BARRETO, 2007, p.47)

Esse conjunto de diferentes características endógenas e exógenas, que fazem as pessoas se enquadrarem em uma situação matutina, vespertina ou intermediária, recebe o nome de cronotipos. Segundo Menna Barreto (2003), existem evidências que estas características que constituem o cronotipo das pessoas são herdadas, tendo, portanto, um componente genético, sendo assim, pouco provável que sejam advindas de experiências de vida.

Ainda segundo esses autores (2007, p. 48), “O cronotipo não se modifica apenas com a adoção de modificações de nossos hábitos. Indivíduos matutinos não se 'acostumam' com hábitos vespertinos e vice-versa". E acrescentam, ainda, que cerca de $10 \%$ das pessoas são matutinas e outros $10 \%$ vespertinas, as demais são caracterizadas como intermediárias.

Os autores colocam ainda que o cronotipo está fortemente influenciado pelo período endógeno das pessoas. Período este que é delineado pela

[...] medida dos ritmos da temperatura corporal ou de hormônios como a melatonina ou o cortisol. (...) Matutinos apresentam menores períodos endógenos quando comparados aos vespertinos. De maneira simplificada poderíamos dizer que as pessoas com o período endógeno menor que 24 horas teriam uma tendência à matutinidade enquanto aquelas que possuem $\mathrm{o}$ período endógeno maior que $24 \mathrm{~h}$ tenderiam à vespertinidade (LOUZADA; MENNA-BARRETO, 2007, p. 50). 
Assim sendo, é possível constatar implicações que tais condições exercem no cotidiano das pessoas. No entanto, o sono é pouco considerado como fator de importância em nossa sociedade, pois de acordo com Coren (1996, p 12) “A visão de que dormir é quase indecente, além de ser um desperdício, é quase universal".

Ainda segundo o mesmo autor, as mudanças no estilo de vida e a luta pela sobrevivência traçaram um caminho diferente de nossas mudanças físicas, de modo que nossas necessidades biológicas seguem, diversas vezes, em descompasso com nossas necessidades sociais.

Assim, percebe-se que os fatores sociais exercem forte influência sobre as escolhas e, principalmente, sobre a ordenação do tempo, contudo, como apontam Louzada e Menna Barreto

Não se trata de uma oposição entre os fatores biológicos e sociais, o mais provável é que estejamos diante de uma interação entre esses fatores que acaba se somando e gerando problemas. Os fatores biológicos, que tendem a atuar a médio e longo prazo, tendem a ser mais silenciosos ou menos evidentes, já os fatores sociais estão nas manchetes dos nossos cotidianos (LOUZADA \& MENNA BARRETO, 2007, p. 82).

Nesse sentido, as implicações sociais desses processos biológicos também se tornam alvo de pesquisa e é possível encontrar materiais sobre a relação desses osciladores temporais endógenos com a vida escolar, com o trabalho e com alguns outros aspectos da vida social.

Nesse contexto, correlacionar as variáveis cronobiológicas ao tempo do lazer, apresenta-se como uma possibilidade de entendimento e empoderamento pessoal, uma vez que não existam estudos que abordem as modulações das características biológicas e suas consequentes restrições às práticas de lazer.

Essa pesquisa teve como proposição o estudo das possíveis influências da condição vespertino/matutino nas práticas de lazer de alguns indivíduos, bem como a análise das possíveis formas de reordenação da rotina diária de trabalho e lazer.

Além disso, verificou-se a possibilidade da existência de um lazer típico do indivíduo matutino, diferentemente do lazer vespertino e a possível interferência de alguns papéis sociais nestas escolhas. 


\section{Métodos}

O método de História Oral foi escolhido, pois permite um diálogo com os indivíduos envolvidos, bem como uma maior aproximação com suas vivências, com o cotidiano e com seus costumes, por meio de suas percepções. Para esta pesquisa optou-se pela utilização da História Oral Temática, uma das técnicas da História Oral, pois pressupõe a delimitação de um tema e a busca de indivíduos que vivenciaram a situação e que pudessem contribuir com seus depoimentos.

A delimitação do objeto de estudo ocorreu de forma não probabilística e intencional (BRUYNE, 1977), sem restrições de idade, gênero ou ocupação. A pesquisa contou com a colaboração de dez pessoas, sendo cinco caracterizadas como vespertinas e cinco como matutinas.

A colaboradora um, caracterizada como matutina, tinha vinte e oito anos, morava com os pais na cidade de São Paulo e dividia seu tempo entre trabalho e estudo todos os dias das $08 \mathrm{~h}$ às $17 \mathrm{~h}$ horas e também se dedicava às aulas de inglês às segundas-feiras à noite.

A colaboradora dois, caracterizada como matutina, tinha vinte e um anos, morava com seus pais na cidade de Mogi das Cruzes, trabalhava e estudava durante o dia no decorrer da semana e aos sábados tinha aulas na Faculdade em que cursava Psicologia.

A colaboradora três, caracterizada como matutina, tinha vinte e cinco anos, morava em uma república na cidade de São Paulo e era aluna do curso de Gerontologia do período vespertino, conciliava seus estudos com estágio em um laboratório dois dias por semana pela manhã.

A colaboradora quatro, caracterizada como matutina, tinha dezesseis anos e morava com os pais na cidade de Tatuí e estudava no período da manhã.

O colaborador cinco, caracterizado como matutino, tinha vinte e cinco anos, morava na cidade de São Paulo com os pais, trabalhava durante o dia e à noite era estudante do curso de Lazer e Turismo.

O colaborador seis, caracterizado como vespertino, tinha vinte anos, morava sozinho na cidade de Tatuí e fazia cursinho pré-vestibular no período da noite. 
A colaboradora sete, caracterizada como vespertina, tinha quarenta e sete anos, dois filhos, divorciada e morava sozinha na cidade de Tatuí e não exercia atividades regulares de trabalho formal.

A colaboradora oito, caracterizada como vespertina, tinha quarenta e oito anos, morava em São Paulo com o filho, divorciada e trabalhava em casa em uma empresa própria online.

O colaborador nove, caracterizado como vespertino, tinha vinte anos, morava em São Paulo em uma república, estudante do curso de Lazer e Turismo no período vespertino e não exercia atividades de trabalho.

A colaboradora dez, caracterizada como vespertina, tinha vinte anos, morava com os pais na cidade de Poá, estudante do curso de Lazer e Turismo no período noturno e trabalhava durante todo o dia.

A técnica da História Oral, segundo Meihy (2005), pode fazer uso de formulários diretos e indutivos ou indiretos e dedutivos. Neste caso, foram utilizados formulários indiretos e dedutivos que, ainda segundo o mesmo autor, são “[...] marcados sempre de grande complexidade, as questões buscadas devem ser sempre contextualizadas e seguir uma ordem de importância capaz de inscrever os tópicos principais em análise do depoente" (p. 164).

É importante destacar que os nomes dos colaboradores foram preservados por questões éticas e optou-se pela identificação por números seguindo critério de ordem de citação na análise dos discursos.

A técnica de História Oral Temática conta com elaboração de um roteiro temas a serem abordados. Para o acompanhamento das pesquisas, um diário de campo foi utilizado. As entrevistas foram realizadas com o total de dez pessoas, de diferentes idades e ocupações, sendo cinco caracterizadas, por meio do questionário H.O. (Horne \& Ostberg), como vespertinas e cinco como matutinas.

O questionário H.O. foi elaborado em 1976 e, para sua elaboração, foi considerada a relação entre os ápices de temperatura oral de diferentes indivíduos, matutinos, vespertinos e intermediários e a coincidência desses fatores com as respostas a determinadas perguntas propostas no questionário. Atualmente, segundo Duarte (2007), pesquisadores de todo o mundo utilizam esse questionário para identificação dos cronotipos. 
Todas as entrevistas obtidas foram transcritas integralmente e analisadas de acordo com o roteiro delineado como instrumento para a técnica da História Oral Temática, esse roteiro contou com os seguintes temas: obrigações pessoais; qualidade do sono; caracterização temporal do lazer e caracterização social do lazer.

\section{Resultados}

Atualmente, como reflexo da Revolução Industrial, tem-se a fragmentação do tempo social e sua limitação em diferentes esferas, tais como o tempo obrigatório e o tempo de lazer. Dumazedier, em seu livro "A revolução cultural do tempo livre”, denomina o tempo linear, pautado no relógio, de monocrônico e estabelece como policrônico o tempo que dá possibilidades à instabilidade e aos "caprichos do imaginário" (DUMAZEDIER, 1995, p. 100).

De acordo com Camargo (1992), entende-se que essa possível liberdade dentro do tempo livre não seja, de fato, autônoma, uma vez que é influenciada por inúmeros fatores sociais e culturais. Contudo, é na esfera do tempo livre que se encontram as maiores possibilidades para a livre escolha.

No discurso de todos entrevistados percebeu-se a fragmentação do tempo e a divisão em horários de trabalho e de lazer, embora os limites entre um e outro tenham sido colocados de diferentes formas.

\section{Matutinidade, Vida e Lazer}

\subsection{Obrigações pessoais e reorganização diária}

Nas pessoas de característica matutina, percebeu-se maior adequação aos tempos sociais: trabalho durante o dia, lazer durante a noite e também nos fim de semana, bem como nos demais tempos de folga. A rotina segue os padrões estabelecidos pela sociedade e isso se evidenciou em algumas falas, como quando a colaboradora um é indagada sobre a possibilidade de acordar cedo. Sobre isso, ela coloca: "É normal, eu estou acostumada, se pudesse escolher não escolheria outra rotina" ou, na fala da colaboradora dois, quando coloca: “[...] minha rotina é normal” e quando é indagada sobre os horários que escolheria, caso fosse possível, ela coloca praticamente os horários a que já vinha se submetendo. 
Em todos os discursos foi possível perceber a valorização do ser matutino, o que dialoga com os pensamentos expostos por Coren (1996, p.12) quando diz que “A visão de que dormir é quase indecente, além de ser um desperdício, é quase universal", e também por Louzada e Menna Barreto (2007) quando dizem que é fácil perceber que a organização social privilegia os indivíduos matutinos, considerando-os mais trabalhadores e menos preguiçosos. Essas afirmações são corroboradas por ditos populares como "Deus ajuda quem cedo madruga".

Ainda de acordo com Louzada e Menna Barreto (2007), em algumas situações, as preferências individuais correspondem com as biológicas, mas em outras, a adaptação é bastante complicada e, por vezes, até inexistente. Como se pôde observar, em uma sociedade pautada pela produtividade, os indivíduos matutinos têm maior facilidade de adequação ao trabalho, uma vez que trabalham em seu tempo de melhor disposição, na maioria das vezes pela manhã, ou à tarde em alguns casos. No período da noite, quando já estão "fadados ao cansaço" e com menos disposição optam por ter seus momentos de lazer, os quais ficam restritos e prejudicados, respondendo mais a impulsos sociais que a realização pessoal.

Como a maioria dos entrevistados trabalhava durante a manhã, algumas vezes, mesmo tendo facilidade em acordar, a rotina tornava-se difícil, pois algumas atividades se prolongavam até a noite como nos casos dos colaboradores cinco e dois que estudavam no período noturno.

O discurso da colaboradora quatro também retratou essa situação quando ela afirmou que "quando eu durmo tarde, na sala (de aula pela manhã), há momentos que eu não sou eu, que eu não presto atenção na aula."

Em contrapartida, a colaboradora dois relatou que se sentia bem e até preferia ter seu período de lazer à noite, mesmo sendo matutina. Em seu discurso, o dia estava bastante atrelado à produtividade e à rotina. Ela disse que não se sentia bem em levantar cedo para algumas atividades de lazer, mas para trabalhar ou estudar não teria o menor problema, em suas palavras: "eu coloquei em minha cabeça que manhã é para trabalhar". Seus horários diários eram ocupados, em grande parte, por obrigações, a noite era o único período que encontrava possibilidades para prática de atividades de lazer ligadas a sua escolha. Desta forma, sua preferência ao lazer noturno se fez evidente, pois, mesmo sendo matutina, seus horários sociais permitiam apenas essa opção. 
Nesse grupo de pessoas, os programas de lazer concentravam-se, geralmente, aos fins de semana, quando eles não precisavam se preocupar com as obrigações do dia seguinte. Nesses dias, seus ritmos não sofriam grandes mudanças, todos os colaboradores continuavam acordando consideravelmente cedo, mesmo quando iam dormir tarde e, nesse período da manhã, quando não tinham suas obrigações e nem a companhia da maior parte dos amigos, optavam por atividades de lazer de cunho mais pessoal. $\mathrm{O}$ colaborador cinco se dedicava à prática de esportes; a colaboradora dois, ao levantar, preferia ler um livro; a colaboradora três gostava de caminhar nas manhãs de domingo e a colaboradora um preferia sempre o lazer pela manhã.

A colaboradora quatro, durante seu período de férias, acordava sempre cedo, e por isso, optava por procurar uma academia. Em suas palavras "[...] eu tento até dormir mais tarde pra poder aproveitar, só que eu gosto de acordar cedo, daí eu vou na academia de manhã”.

Em algumas falas, perceberam-se alguns aspectos que demonstravam o quão agradável é acordar cedo, corroborando com o status social da matutinidade. Como na fala da colaboradora dois: "[...] querendo ou não a gente sempre se espelha em um amigo nosso e em alguém que a gente vê que é batalhador, que faz isso, faz aquilo”. Ou, quando a colaboradora três colocou: “[...] minha irmã tem um sério problema, gosta de dormir demais, ela gosta de descansar [...]" ou, em outro trecho quando diz: "eu não tenho problemas de sono. Sono e comida, que todo mundo reclama, acho que sou meio anormal. Eu não tenho preocupação com isso...(risos)."

Por fim, a reorganização diária dos indivíduos matutinos, em função de seu cronotipo, não se fez muito evidente, pois eles se enquadravam no contexto social esperado.

Os seus horários de lazer não eram prioridade, uma vez que os períodos de maior disposição biológica coincidiam com os períodos de maior exigência produtiva. Desta forma, grande parte das atividades de lazer se caracterizava como de cunho social, nos horários socialmente estabelecidos para isso, e as atividades de cunho pessoal, tinham destaque em momentos como finais de semana e feriados. 


\subsection{Manhã ou noite? Por onde andam os matutinos em seu tempo de lazer?}

De acordo com os depoimentos, o dia estava sempre atrelado à produtividade, embora a vontade da maior parte dos matutinos entrevistados tenha sido praticar atividades de lazer pela manhã, essa opção foi negligenciada e renegada, uma vez que os horários sociais apontam o período da manhã e da tarde como horário destinado ao trabalho e às obrigações.

A colaboradora um disse: "[...] eu aproveito mais o dia, eu consigo fazer minhas coisas durante o dia, trabalhar, tipo fazer alguma atividade de lazer, sair, durante o dia. [...] eu prefiro a noite para relaxar, dormir". Percebe-se aí sua preferência pelo dia, inclusive para atividades de lazer, contudo, ela trabalhava todos os dias durante a manhã e tarde, e no sábado de manhã, geralmente, ajudava suas irmãs com as tarefas domésticas. Embora sua preferência fosse pelos tempos de lazer matutino, suas possibilidades para escolher uma atividade de lazer nesse período eram restritas.

O mesmo aconteceu com o colaborador cinco quando coloca que sua principal atividade de lazer era a prática de esportes e, sempre que podia, fazia isso pela manhã. Dizia ainda que “[...] se eu puder preferir entre sair à noite e acordar cedo, eu prefiro acordar cedo, para praticar esporte".

Assim, para o lazer, os horários comumente utilizados eram os fins de semana e tempos mais prolongados de folga, como férias e feriados. Para alguns, lazer à noite era uma tarefa muito difícil, pois exigia um esforço em ficar acordado durante a noite e um esforço ainda maior no dia seguinte para se manter disposto.

A colaboradora três, embora tivesse seu tempo de lazer, essencialmente, nos fins de semana e tempos de folga durante a semana, tentava conciliar seus desejos individuas com a vontade de seus amigos em partidas de baralho a noite, horário comum entre eles.

As atividades de lazer dos matutinos estavam, frequentemente, associadas às situações relacionadas ao sol, ao verão, como caminhadas, prática de esportes ao ar livre, visitas a clubes ou sítios, à academia. Pouco apareceu nos discursos atividades consideradas mais "boêmias" como bares, festas, casas noturnas e, quando apareciam, estavam relacionadas ao convívio social e não à prioridade de escolha pessoal. Talvez, porque tais atividades sejam, 
frequentemente, oferecidas no período noturno, quando essas pessoas não estão em seu "mais confortável" e prazeroso estado físico.

As pessoas matutinas analisadas têm diferentes perfis e realidades, mas a matutinidade, como observado, atua delineando alguns aspectos de suas vidas, o que influencia, na maior parte das vezes, inconscientemente, a organização de sua rotina e a definição de algumas opções de lazer.

\subsection{Lazer e matutinidade}

O ser humano, como já apontado por Louzada e Menna Barreto (2007), é uma espécie essencialmente diurna, que oscila entre a matutinidade e a vespertinidade. Embora, cronobiologicamente, exista essa variação, a estrutura social atual é organizada, ainda segundo os mesmos autores, em torno de uma lógica matutina. Estrutura esta, criada culturalmente e mantida, dia a dia, por hábitos, instituições e convenções.

Como já discutido anteriormente, esta estrutura social coloca o trabalho ou o tempo de produtividade em uma relação direta com o dia, valorizando- o exatamente pelo seu caráter produtivo e a noite, por sua vez, é interligada com o tempo de livre, de não trabalho.

Neste sentido, o tempo de lazer, que muitas vezes fica restrito às noites, teve um papel secundário na vida das pessoas matutinas, pois neste período já não se sentiam dispostas e optavam por se sentir bem no dia seguinte.

É importante notar que todos os colaboradores trabalhavam durante o dia e tinham o seu período de tempo livre à noite. Nota-se, também, nas falas a indisposição, inclusive física, para o lazer, o que está diretamente relacionado com a percepção de qualidade deste lazer. Embora alguns preferissem seus momentos de lazer pela manhã, esta prática era restrita por conta dos horários, e este período ficava então, limitado aos fins de semanas, feriados e férias.

Quando questionadas sobre a importância do lazer em suas vidas todos os colaboradores, com exceção da colaboradora três, relacionam essa importância ao descanso, à reposição de forças para o trabalho, como podemos verificar nos seguintes trechos:

Para a colaboradora dois: 
[...] Às vezes eu conto as horas, eu conto os minutos, os segundos, pra chegar àquele determinado hora do dia, sete horas da noite, oito horas pra eu ver aquela pessoa, sair sabe?! Ir pra um lugar legal ler um livro ...que as vezes eu to no trabalho e não pode, tem que fazer o seu trabalho então pra mim a importância do lazer é essencial na minha vida porque sem ele sei lá..eu estaria bem piradona ...é super legal.

Para a colaboradora quatro:

[...] ah...total, depois que eu comecei a estudar certo assim, se eu não saio, eu fico louca em casa, eu não aguento mais ficar em casa e eu acho que é importante descontrair, sair do ambiente de trabalho, de tudo....

Considerando toda essa lógica, relacionada ao trabalho e essencialmente ao dia, pôde- se perceber as dificuldades encontradas por estes indivíduos em ter e aceitar um tempo de lazer legítimo, que responda também aos seus anseios e disposição pessoais. Ora este tempo estava diretamente relacionado aos encontros sociais, que acontecem, geralmente, à noite, ora estava relacionado mais às vontades pessoais. Em ambos, estavam implícitos diferentes esforços: de se adaptar ao meio social ou de sustentar atividades solitariamente.

Isto posto, percebe-se que, embora a importância do lazer não seja negada na maior parte dos discursos (principalmente quando o questionamento é diretamente sobre esta importância), no decorrer das falas inúmeros elementos apontam para a manutenção de atividades de lazer em segundo plano na vida e que pouco correspondem aos elementos básicos de Desenvolvimento, Descanso e Diversão apontados por Dumazedier (1980).

As atividades de cunho mais pessoal convergem a essa direção, as demais estão fortemente atreladas ao caráter compensatório obtido nessas atividades com a finalidade de repor forças e ânimo para o trabalho.

\section{Vespertinidade, Vida e Lazer}

\subsection{Obrigações pessoais e reorganização diária}

Embora o cenário social para o convívio de pessoas matutinas e vespertinas seja o mesmo, a organização pessoal da vida das pessoas estudadas foi retratada de diferentes formas. 
Enquanto as pessoas matutinas tinham maior facilidade em organizar seus horários biológicos com os estipulados pela dinâmica social, as vespertinas despendiam um esforço muito grande em traçar alternativas as essas dinâmicas.

A temática da produtividade também se fez presente nesses discursos quando os colaboradores vespertinos expressavam a tentativa de reorganização de seus horários, optando por realizar suas atividades obrigatórias à noite ou à tarde, no período em que estavam mais dispostos.

Nesse sentido, o colaborador seis diz:

[...] eu comecei a procurar um horário de estudo que eu rendesse mais, eu comecei buscar e eu percebi que acordar $8 \mathrm{~h}$ não era a minha praia, então eu preferi chegar à noite, tomar um banho, depois da aula, tomar um café, alguma coisa e estudar até às $3 \mathrm{~h}, 4 \mathrm{~h}$ e dormir até $12 \mathrm{~h}$, pra mim é melhor.

A colaboradora sete, comentando também sobre esse tema, disse: "às vezes eu tenho um compromisso, tenho coisa pra fazer eu deixo pra fazer na parte da tarde, porque de manhã eu não consigo fazer muita coisa."

A colaboradora oito, era sócia de uma empresa de vendas de produtos on-line, ela disse: "às vezes, duas horas da manhã eu tô trabalhando, não que seja necessário mas eu não tô com sono, não tem nada pra fazer eu já vou adiantando."

Como a maior parte dos colaboradores tinha seus horários destinados às obrigações pela manhã ou pela tarde, o período da noite era um horário livre para grande parte dessas pessoas, contudo, a necessidade do trabalho no dia seguinte, pela manhã, fazia com que as opções de lazer se concentrassem, principalmente, nos finais de semanas. Contudo, como os vespertinos mantinham seu ritmo noturno todos os dias, sendo impossível transformar todos esses horários em vivências de lazer, acabavam, algumas vezes, por criar alternativas de produtividade.

Diferentemente dos matutinos, percebeu-se nos discursos vespertinos uma tentativa de justificativa pela "escolha" de seus horários, retratada em palavras e gestos. Percebeu-se a tentativa de adequação no discurso do colaborador seis, por exemplo, quando disse que "preferia acordar cedo, se eu conseguisse acordar cedo, eu preferia acordar umas $07 \mathrm{~h} 30,08 \mathrm{~h}$ e 
estudar até $12 \mathrm{~h}$ e dali chegar da escola e dormir." Ou nas falas do colaborador nove, quando disse:

Ó, eu gosto de acordar cedo. E acho que o dia rende mais. Só que não consigo, mano. Se eu acordo cedo parece que rende mais mesmo, é diferente você acordar às $8 \mathrm{~h}$ e você acordar às $11 \mathrm{~h}$ (...) quando eu consigo acordar cedo eu gosto, só que eu tenho dificuldades, não consigo mesmo, são físicas. Não sei o que acontece [...]

Nos discursos das colaboradoras sete e oito, pode-se identificar o descontentamento com os horários sociais como quando a colaboradora sete disse "As pessoas acham que todo mundo tem que ter o mesmo tempo, o mesmo, acordar de manhã e dormir no mesmo horário e não é assim." O discurso da colaboradora oito corroborou, quando ela pontuou:

[...] se o ambiente tiver quieto, o telefone não tocar ou nada pelo menos até umas dez horas eu durmo, porque daí você vê, pra quem já foi dormir uma (e uma é cedo...) duas horas, por exemplo, até as dez, quer dizer, são oito horas de sono. Se você pensar que levanta às dez horas é tarde, mas você precisa ver também a hora que a pessoa foi dormir, né?! É isso... às vezes a pessoa fala "Ah, fulano é vagabundo levanta dez horas" mas e a que horas ele foi dormir?

Em todos os discursos foi possível identificar fatores que demonstravam o não enquadramento social. O colaborador nove apontou claramente isso quando disse: "eu acho que o dia funciona mesmo de manhã viu, eu acho que o mundo funciona de manhã [...]" e conclui "a noite é o mundo de ressaca". Nessas frases, percebeu-se a concepção do dia como cerne de todas as atividades obrigatórias, de toda produtividade e a noite como conclusão disso tudo, quando tudo e todos já estão exaustos.

E, por fim, ele pontuou o que sente em relação a isso, dizendo: “eu não gosto de acordar tarde porque eu não gosto de ficar dormindo enquanto tudo está acontecendo, o pessoal trabalhando, tudo acontece de manhã, por isso que eu gosto de acordar cedo".

Além dos fatores relacionados a não adequação social estavam, também, presentes nos discursos fatores como o "mal-estar" físico e psicológico por se submeterem a tempos sociais, diferentes de seus tempos biológicos. A colaboradora dez, por exemplo, colocou "eu não gosto de acordar cedo, não gosto, não me sinto bem... queria dormir mais". 
A colaboradora oito, neste sentido, também, disse:

[...] de manhã eu não gosto, não gosto de marcar nem dentista, nada de manhã. Não gosto. Eu vou se eu tiver que ir [...] depois que eu acordei, lavei o rosto, levantei, aí tudo bem [...] o duro é que você fica [...] com um pouco de mau humor.

Por fim, a colaboradora sete, disse: “[...] de manhã é complicado pra mim, eu não gosto, eu tenho muito sono, eu tenho muito frio, eu não me sinto bem de manhã. Pra mim, a manhã deveria ser o período que o pessoal normalmente usa pra dormir”.

Esse descontentamento ao se adequar ao período matutino aparece correlacionado a uma vontade de adequação a realidade social, pois apesar dessa busca pela adaptação, existem alguns horários que dificilmente podem ser alterados e que pressupõem uma adequação, como horário de bancos, correios, escolas, etc.

Para tais indivíduos, embora as vivências de lazer estivessem concentradas nos fins de semana, feriados e férias encontravam também, durante a semana, um maior tempo potencialmente livre, pois diferente dos matutinos, os vespertinos vivenciavam o dia para além dos horários sociais estipulados como obrigatórios, tendo assim, a "opção" de escolher ou não vivências de lazer, uma vez que nesse período ainda se sentiam dispostos. Por vezes, vivenciavam esses momentos de forma mais solitária, uma vez que os horários sociais levam grande parte das pessoas a dormir cedo, para acordar cedo no outro dia.

Nos fins de semana, a maior parte dos vespertinos dorme pela manhã e concentra suas atividades tanto de lazer como obrigatórias nos períodos da tarde e da noite. A maior parte dos colaboradores tem uma flexibilidade maior de horários durante a semana, trabalha no período da tarde ou à noite. Dessa forma, nos fins de semana, apesar de dormir e acordar ainda mais tarde, mantinham outras atividades durante o dia.

Contudo, em alguns casos, como durante a semana o esforço de adequação era maior, o fim de semana ficava destinado a extensas horas de sono como se pode observar no discurso do colaborador nove: "se eu tenho um compromisso domingo às $14 \mathrm{~h},[\ldots]$ eu só acordo na hora mesmo, porque a semana é muito puxada (...) fim de semana se eu tenho tempo pra dormir, eu durmo (...)." 
Considerando o ser humano como um ser diurno, como apontado por Louzada e Menna Barreto (2007), identifica-se que as atividades sociais estão concentradas durante o dia, e nesse contexto, os vespertinos precisam de um esforço maior de (re)organização da rotina para alcançar uma situação de bem-estar tanto biológica como social.

\subsection{E por onde andarão as corujas?}

As atividades de lazer, de acordo com Dumazedier (1980), têm como um de seus pressupostos básicos a livre escolha e, como já pontuado, percebeu-se que esta livre escolha é relativa, pois está diretamente influenciada por inúmeros fatores sócio-culturais.

As vivências de lazer no período da manhã apareceram, na maior parte dos discursos, como algo a ser evitado. Nos períodos em que se observava tempo livre como nos fins de semana, feriados e férias as manhãs apareceram como um momento para dormir ou descansar. $\mathrm{O}$ colaborador seis apontou que para ele "[...] lazer de manhã é dormir [...]” Neste mesmo sentido a colaboradora dez também disse que "[...] de manhã, se não tiver nenhum outro compromisso no fim de semana, eu quero dormir até mais tarde, tipo às $10 \mathrm{~h}$ ou $11 \mathrm{~h}[\ldots]$ ”.

Como os matutinos, os vespertinos também procuravam se adequar a horários sociais de lazer e a seu meio, então, embora a preferência por atividades de lazer à noite fosse presente em unanimidade em todos os discursos, quando havia necessidade de acordar cedo para alguma vivência de lazer, por se tratar de algo esporádico, não apareciam grandes resistências.

O colaborador nove, embora, tivesse reconhecido que prefere atividades de lazer à noite, disse que acha atividades de lazer pela manhã importantes, em suas palavras "acho que de manhã é melhor, me faz acordar mais cedo [...] sempre tentei fazer com que à noite ficasse livre [...]”. Percebeu-se, ainda nesse trecho, mais uma vez, a necessidade de adequação, pois embora já tenha deixado claro o quanto não se sentia bem acordando cedo, insistiu em que é a melhor opção e, que ele não conseguia se adequar a isso. Ainda nesse sentido, seguiu dizendo:

[...] à noite você fica cansado do resto do dia, você vai lá faz atividades de lazer. Eu acho que desenvolve um pouco menos porque você já está cansado, depois da atividade de lazer você dorme de manhã e, então, é uma difícil para você acordar, porque daí você está cansado [...] 
Em contrapartida, o discurso dos outros colaboradores valorizou o período da noite em relação ao da manhã para atividades de lazer, como pontuou a colaboradora sete: "eu me sinto bem à noite, eu tenho um "pique" que você não acredita, ninguém acredita que eu sou a mesma pela manhã, a noite eu tô elétrica, eu consigo acompanhar mais à noite o pessoal do que durante o dia".

O colaborador seis, sobre a noite, disse "eu tô mais tranquilo, não tô com sono mesmo, tô de boa, da hora, eu curto". A colaboradora dez, nesse sentido, também se expressou dizendo: "a noite é o período que mais gosto... gosto de comer coisas gostosas, a noite é o período que mais gosto, mesmo porque não estou trabalhando".

Nesses trechos percebeu-se a disposição e a preferência desses indivíduos por vivências de lazer no período da noite, além da adequação de atividades de lazer a esse período, como é possível perceber nas falas da colaboradora sete: “a gastronomia é para mim um lazer, me faz muito bem. Mas eu prefiro fazer à noite, eu prefiro fazer um jantar do que um almoço [...]".

Também foi recorrente, no discurso dos vespertinos, a referência às atividades "boêmias", como bares e festas noturnas, essa preferência pode estar associada ao fato que atividades de lazer sejam oferecidas, principalmente, no período da noite. Esse período caracteriza-se, então, como um ponto chave no lazer dessas pessoas, trazendo possibilidades não apenas de descanso, mas, também, de divertimento e de desenvolvimento.

\subsection{Lazer e vespertinidade}

O ser humano, embora seja um ser diurno, apresenta algumas variações e pode tender a hábitos vespertinos e, neste ínterim, pode se estabelecer o descompasso entre os ritmos massificados da sociedade e os ritmos individuais. Sobre isso, Coren (1996) diz que as mudanças de nossas necessidades fisiológicas podem seguir em descompasso com nossas necessidades sociais. Para ele,

Devido ao cronotipo, o horário de trabalho ou escolar único afeta de maneira distinta a vida das pessoas. Para algumas pessoas, o horário acerta "em cheio" com as preferências individuais e tende a ser bem assimilado. Para outras pessoas, o ajuste necessário exige um enorme esforço do organismo, sendo que, muitas vezes, a adaptação não é possível. Não precisamos ir longe para constatar que nossa organização social privilegia os indivíduos 
matutinos, que, consequentemente, são considerados mais trabalhadores e menos preguiçosos (1996, p 12).

Considerando estas afirmações, foi possível entender o contexto em que os discursos se inserem, contexto de uma vida matutina que os vespertinos tentam se enquadrar. Essa tentativa de enquadramento apareceu em diversas instâncias dos discursos, na supervalorização do trabalho como forma de auto-afirmação e até na negação do lazer, que aparece, muitas vezes, como algo secundário ou indigno.

Verificou-se tal constatação nas palavras do colaborador nove, por exemplo, quando negava a importância do lazer em sua vida e depois tentava afirmar a importância das atividades matutinas, mesmo sendo vespertino.

Quando questionado sobre como se sentia ao optar por atividades de lazer pela manhã disse:

Lazer de manhã? Ah é melhor, viu? Você fica mais disposto. Porque se faz uma coisa que você quer, uma atividade de lazer de manhã, você já, de certa forma, se realiza do dia né, já fica mais solto, mais leve, desenvolve já, é sua atividade, você mesmo, é melhor assim, por exemplo, quando eu jogava bola, eu jogava de manha, depois de jogar bola eu ficava bem melhor assim, do que à tarde.

Sobre atividades de lazer à noite, pontuou:

A noite você fica mais cansado do resto do dia, aí você vai lá faz atividades de lazer. Eu acho que desenvolve um pouco menos porque já tá cansado, depois da atividade de lazer você já dorme e de manhã é uma coisa mais pra você acordar mesmo, é uma coisa que você vai estar mais cansado.

Como foi possível observar, a necessidade de se enquadrar em um discurso matutino continuava presente, quando tentava justificar uma organização diária que julgava importante e à qual não se adequava. Neste contexto, as atividades de lazer foram retratadas como secundárias, pois em primeiro plano estava a necessidade de se afirmar como um ser adequado socialmente que, mesmo em outros ritmos, ainda era trabalhador e produtivo.

Outras questões também se destacaram nos discursos quando os colaboradores falavam sobre a importância do lazer em suas vidas. Uma delas é a retratação de como o lazer é um tempo importante para reposição de forças para o trabalho. Outra questão que teve destaque nos 
discursos foi o fato das vivências de lazer estarem, em grande parte, relacionadas à momentos de socialização e por essa característica específica acabava adquirindo real importância para os envolvidos.

No discurso do colaborador nove verificou-se que, apesar do reconhecimento do lazer como elemento importante, existia a necessidade de construir um discurso que negue tal importância. Como retratado no trecho:

Olha é meio secundário, viu? Mesmo estudando lazer e turismo, a gente sabe a importância do lazer, devido à correria assim, encaro o lazer como uma tentativa, não como uma necessidade. Às vezes eu acho que é mais importante trabalhar, cuidar da casa do que uma atividade de lazer, você só tem atividade de lazer se tem tempo, né? E é raro isso, atividade de lazer tem que ser programada no meio de todas as tarefas, que é uma coisa totalmente necessária pro desenvolvimento humano, só que eu não encaro isso, eu fico diretão na faculdade tudo isso, mas na prática, lazer só quando dá. Isso é um problema.

Nas falas do colaborador seis percebeu-se que o lazer foi retratado de forma instrumental, como um meio de reposição de para que fosse possível realizar as atividades obrigatórias satisfatoriamente. Segue, em suas palavras:

(Sobre a importância do lazer) ${ }^{4}$ Ah, quesito de tranquilizar um pouco, porque assim, eu tô no terceiro ano de cursinho, fico longe de pai, mãe, fico longe de família, sou monitor ainda, tem gente que pensa que não faz nada, que fica sabe, só querendo zoar, então à noite, quando eu tô ali tranquilo, curtindo, mesmo, o meu horário de lazer é pra mim, sossegadão, é o horário que eu tenho pra mim. É o que ajuda a lidar com as coisas, se eu não tivesse esse momento, sozinho, às vezes, sabe tranquilo, eu não conseguiria continuar, assim, entendeu, ainda, continuar no cursinho, desistiria e pagaria uma faculdade. Então isso me ajuda a amenizar um pouco, o que eu sofro de manhã trabalhando, vamos dizer assim, à noite eu tranquilizo

A colaboradora oito fez seu discurso no sentido da valorização do lazer como espaço de vivência social, como se percebe no seguinte trecho:

\footnotetext{
${ }^{4}$ Nota da autora

${ }^{5}$ Grifo da autora
} 
$(\text { Sobre lazer })^{6}[\ldots]$ ah muito importante. Eu faço questão de ter... se eu ficar muito tempo sem sair, sem ir pra uma balada com meu namorado, sabe encontrar pessoas, dar risada... é péssimo, parece que eu não estou participando da sociedade, da vida, da rotina de tudo, eu me sinto excluída assim, eu gosto eu acho importante. Sair na casa dos meus familiares, fazer um churrasco com todo mundo, eu acho que faz parte...né?! pra mim é super importante, eu não me imagino enfornada dentro de casa, sem sair, sem lazer....acho que é importante...

Tendo em vista essa restrição do lazer aos finais de semana, existe outro fator relevante: o fato das pessoas vespertinas possuírem menos horas de sono durante a semana, uma vez que, tentando se adaptar aos horários sociais, acordam cedo e vão dormir tarde, respondendo as demandas de seu corpo. Assim, nos finais de semana a tendência é "repor" esse tempo de sono perdido, então em parte do tempo que tem disponível, optam por dormir.

Em todos os discursos foi possível notar que, quando se referiam aos finais de semana, havia sempre uma menção ao descanso, relacionado ao sono, ou as horas destinadas a dormir. Fato que não acontece com os matutinos, que tinham, aos fins de semana, uma opção para escolher atividades de lazer pela manhã.

Assim, foi possível constatar que para os vespertinos o lazer aparece como atividade secundária, sendo atrelado, por vezes, à reposição de forças para o trabalho ou à reposição de horas de sono ou, ainda, aos momentos de socialização. Ao contrário do discurso matutino, não houve entre os vespertinos muitos apontamentos sobre opções de lazer de caráter mais individual.

\section{Considerações Finais}

O ser humano, essencialmente diurno, não possui um horário biológico padronizado, existem indivíduos matutinos, que tendem a dormir e acordar mais cedo e indivíduos vespertinos, que tendem a dormir e acordar mais tarde. Esses ritmos biológicos, objeto de estudo da cronobiologia, são gerados por características endógenas e recebem influencias externas, sendo, portanto, modulados. Tais características, denominadas cronotipos, exercem inúmeras

\footnotetext{
${ }^{6}$ Nota da autora
} 
influências em diferentes esferas da vida. Essa pesquisa debruçou-se sobre suas interfaces com o lazer.

Após o estudo, realizado junto a cinco indivíduos matutinos e cinco vespertinos, pôde-se perceber que existe uma reorganização diária nas vivências dessas pessoas em função de seu cronotipo, sendo esta observada, principalmente, nos indivíduos vespertinos que tem seus horários mais distantes dos socialmente estabelecidos. Estes indivíduos procuram horários alternativos de trabalho, concentrando-os no período da tarde ou da noite, e seus horários de lazer se restringem, em maior parte, no período da noite e nos fins de semana, feriados e férias.

Os matutinos apresentaram em seus discursos menor dificuldade em reorganizar seus horários, pois estes estão de acordo com os estipulados pela sociedade. Assim, no tempo em que estão dispostos se dedicam ao trabalho e as atividades obrigatórias e produtivas. O tempo de lazer, durante a semana, apresentou-se comprometido, uma vez que no período da noite eles apresentavam-se indispostos a prática de atividades de lazer. Desta forma, o tempo de lazer fica, também, submetido a fins de semana, férias e feriados.

Nos finais de semana, os vespertinos que trabalhavam pela manhã durante a semana, costumavam utilizar seu tempo livre para descansar, dormir, repor o sono atrasado e, mesmo os que não tinham a rotina de acordar cedo durante a semana, dificilmente optavam por atividades de lazer pela manhã.

Os matutinos, em contrapartida, sustentavam tanto vivências de lazer à noite, para manter um convívio social, quanto pela manhã. As atividades pela manhã concentravam-se, principalmente, em dias de não trabalho e eram opções de cunho mais pessoal e individual.

Notaram-se também nos discursos matutinos a prevalência de atividades de lazer relacionadas ao sol, a caminhadas, prática de esportes, atividades ao ar livre.

Para os vespertinos, apareceram elementos de um lazer "boêmio" relacionado a bares, festas etc. Provavelmente, isso aconteça devido a maior oferta dessas atividades no período de disposição desses indivíduos. Durante a semana, embora existisse uma possibilidade maior de vivências de lazer em comparação com os matutinos, esses períodos eram preenchidos por outras atividades aliadas à produtividade. 
Considerando a importância atribuída ao lazer na vida desses indivíduos, pôde-se verificar que tanto na vida dos indivíduos matutinos como na dos vespertinos o lazer aparecia com caráter compensatório, de reposição de forças para o trabalho ou aparecia atrelado às vivências sociais, a um espaço de encontro com outras pessoas: amigos, famílias, etc.

Como notado, existiam vivências de lazer mais comum entre os vespertinos e outras entre os matutinos, contudo, esses indivíduos, por conta de horários sociais, também compartilhavam horários. Embora os fatores biológicos presentes no cronotipo pudessem exercer certa influência em suas escolhas, os fatores sociais apareciam com maior preponderância, principalmente, pela organização social do tempo que define horários de trabalho, de descanso, de lazer etc. Esses horários eram, segundo os discursos, transgredidos, mas permaneciam, em grande parte, direcionando as escolhas e delineando uma vida social em comum.

\section{Agradecimento}

Aos professores Luis Menna- Barreto, Luís Otávio de Lima Camargo e Valéria Magalhães.

\section{Referências}

BRUYNE, P.; HERMAN, J.; SCHOUTHEETE, M. de. Dinâmica da pesquisa em ciências sociais. Rio de Janeiro: Francisco Alves, 1977.

CAMARGO, L. O. O que é lazer. São Paulo: Editora Brasiliense, 1992.

COREN, S. Ladrões de Sono: Um alerta sobre os riscos de contrariar nosso relógio biológico. São Paulo: Editores Associados, 1996.

DUMAZEDIER, J. Lazer e Cultura Popular. São Paulo: Editora Perspectiva, 3 a ed., 2004.

DUMAZEDIER, J. A revolução cultural do tempo livre. São Paulo: Studio Nobel, 1995.

DUMAZEDIER, J. Valores e conteúdos culturais do lazer. São Paulo: SESC, 1980.

GMDRB- Grupo Multidisciplinar de Desenvolvimento e Ritmos Biológicos. Desenvolvido pela Universidade de São Paulo. DUARTE, Leandro - O questionário do Cronotipo. Apresenta textos e artigos sobre cronobiologia. Disponível em: <http://www.crono.icb.usp.br> . Acesso em: 14 abr. 2007.

LOUZADA, F.; BARRETO MENNA, L. O sono na sala de aula: Tempo escolar e tempo biológico. Rio de Janeiro: Vieira \& Lent, 2007.

MARCELLINO, N. C. Lazer e humanização. Campinas: Papirus, 1987. 
MARCELLINO, N. C. Estudos do Lazer - Uma introdução. $4^{\mathrm{a}}$ ed. Campinas: Autores Associados, 2006.

MENNA BARRETO, L. (Org.). Cronobiologia: Princípios e Aplicações. São Paulo: Editora da Universidade de São Paulo, 2003.

MEIHY, J. Operações da História Oral: Prática. In: Manual de História Oral. 5 a ed. São Paulo: Loyola, 2005.

Recebido em: 08/07/2011

Aprovado em: 15/11/2011 (1 ${ }^{\mathrm{a}}$ versão) $03 / 01 / 2012$ (2 ${ }^{\mathrm{a}}$ versão) 